\title{
Customizing strategy: Policy goals and interest group strategies
}

\author{
Anne Skorkjær Binderkrantz* and Simon Krøyer \\ Department of Political Science and Government, Aarhus University, Bartholins Allé 7, 1350, 224, \\ Aarhus C 8000, Denmark. \\ ASB@ps.au.dk \\ *Corresponding author.
}

Executive Summary Interest groups pursue a wide range of policy goals. In their attempts to realize these goals, groups may lobby bureaucrats and politicians, approach the media and engage in protest activities. This article investigates the relation between the characteristics of policy goals and the strategies of influence utilized by interest groups. Policy goals are captured by four dimensions emphasizing: (i) the divisibility of goals, (ii) the degree of change sought, (iii) the type of interests pursued, and (iv) how technical goals are. The relevance of these dimensions and the effect of goals on influence strategies are tested in a survey of national Danish interest groups. The findings support the importance of group goals as determining strategy. Groups pursuing general interests mainly lobby parliament and the media, whereas groups with technically complicated goals lobby bureaucrats more intensively. The more divisible a goal a group is pursuing, the more actively it engages in all types of influence strategies.

Interest Groups \& Advocacy (2012) 1, 115-138. doi:10.1057/iga.2012.6;

published online 27 March 2012

Keywords: Interest group strategies; policy goals; political arenas

A fundamental raison-d'être for interest groups is to pursue policy goals. Groups are politically active because they want to see their goals fulfilled. And groups are crucial for political science because of their success with sometimes - achieving their goals. This basic observation points to the importance of capturing what it is groups want in politics and how the nature of policy goals affects their policy-relevant activities. When are politicians the prime target of group activities, when do groups approach bureaucrats and which goals lead groups to engage in media-directed activities? These questions inform the theoretical and empirical discussion in this article.

(C) 2012 Macmillan Publishers Ltd. 2047-7414 Interest Groups \& Advocacy Vol. 1, 1, 115-138 www.palgrave-journals.com/iga/ 
In a political context with multiple paths to influence - notably the administrative, the parliamentary and the media arena - interest groups engage in a mix of activities expected to maximize their political influence. Here, it is argued that groups customize their political strategies to the situation at hand. Some policy goals are well suited to capture the attention of the media, whereas others are more easily raised in direct interaction with bureaucrats. While groups may have a general preference for some strategies over others based on group history, ideology or other group characteristics (Gais and Walker, 1991; Grant, 2000a), their goals in a specific situation also affect their choice of strategy. The nature of policy goals pursued is thus a central piece in charting the maneuvering of groups across political arenas.

Generally, factors at three levels affect group strategic choices: the institutional level, the group level and the issue level (Dür and De Bièvre, 2007; Mahoney, 2007). While previous discussions of the issue level have focused on issue characteristics such as saliency and level of conflict (Kollman, 1998; Leech, 1998; Mahoney, 2007), this article investigates the role of the policy goals groups pursue. Two groups active on the same issue can have very different goals. A business group may seek a specific change in policy that will benefit its members, while an environmental group may work to prevent such change to the benefit of the environment. More generally, it is argued that policy goals can be classified via four dimensions: first, whether the goal pursued may only be met fully or not at all or has a more divisible nature; second, whether the group seeks change or protection of the status quo; third, whether the group is pursuing general or more specific interests; and fourth, whether the goal is technically complicated or simple. These different specifications of group goals are expected to affect the influence strategies pursued.

There are two traditional approaches to investigating group activities: surveys mapping group strategies and accounting for systematic variation herein (see, for example, Schlozman and Tierney, 1986; Gais and Walker, 1991; Beyers, 2004; Binderkrantz, 2005; Eising, 2007); or case studies establishing important insight into how specific circumstances shape what groups do and accomplish (for an overview, see Baumgartner and Leech, 1998, Chapter 7). Although case studies are by nature context sensitive, a drawback of many quantitative studies is lack of attention to context. A few path-breaking studies have bridged the gap between these two general approaches either by incorporating contextual factors into quantitative research or by conducting large- $N$ case studies (Kollman, 1998; Leech, 1998; Mahoney, 2008; Baumgartner et al, 2009). This study follows in the footsteps of these studies by investigating group activities in the context of particular issues. In a survey of 579 Danish national interest groups, groups were asked to report on a policy goal recently pursued. Focusing on this we asked about a range of policy goal characteristics as well as the activities the groups have engaged in to pursue 
goal attainment. The empirical analyses demonstrate that policy goals are important. Although systematic differences exist across group types, goal characteristics also affect political strategies. In other words, strategies are indeed custom made.

\section{Theory}

\section{From mapping strategies to attention to context}

The last two decades have witnessed increasing attention to the strategies interest groups use to gain political influence. Although this subject has been of long-standing interest in the US literature (see, for example, Berry, 1977; Schlozman and Tierney, 1986; Gais and Walker, 1991; Heinz et al, 1993), its appearance on the European research agenda is more recent. Here, considerable progress has been made in mapping the utilization of different tactics and strategies. Studies adopting broadly similar typologies of strategies conclude that European interest groups - alongside their US counterparts - are keen users of a broad array of activities, among them classic 'insider' tactics such as lobbying decision-makers and 'outsider' tactics targeting the media. It has also been demonstrated that the use of different tactics and strategies go hand in hand. Rather than being a 'weapon of the weak', media tactics are heavily used by wealthy interest groups with good access to decision-makers (Beyers, 2004; Binderkrantz, 2005; Eising, 2007; Kriesi et al, 2007).

These findings contradict conventional wisdom in European interest group research, which traditionally sees insider access to politics as the main channel of political influence and describes outsider strategies mainly as a weapon used by groups unwilling or unable to gain insider status (Grant, 2000a, 2004). This understanding of the nature of group influence has been central to the main approaches to studying interest groups in Europe. The network approach assumed that groups operating within policy communities were more influential than groups involved in issue networks (Marsh et al, 2009, p. 621), and the underlying theme of the corporatist literature was that corporatist status could be transformed to political influence (Schmitter, 1981; Lembruch, 1982). The empirical findings of widespread use of media strategies even by insider groups therefore present a challenge for European scholars. When a wide repertoire of tactics and strategies are seen as important by groups, accounting for variation in strategy use across groups, countries and issues must be high on the research agenda (Beyers, 2008).

Even though most groups use most strategies, variations in preferred strategy is found across countries and across groups. Direct comparison of different studies is inhibited by different survey populations and questions, 
but there is little doubt that institutional factors at the country level affect group strategies. For example, Kriesi et al (2007, pp. 67-68) report that groups working in closed systems (Spain, France and Italy) value publicoriented activities more than groups operating in more open systems (Germany, the Netherlands, the United Kingdom and Switzerland). Likewise, group type and resources affect the use of strategies. A Danish study has found public interest groups to be most active toward the media, whereas business groups and labor unions rely more on contacts with public servants (Binderkrantz, 2008, p. 185). Further, more confrontational outsider tactics generally seem to be less used than other activities. Activities such as civil disobedience and direct action are used by a minority of groups and these groups are less active toward, for example, public servants than other groups (Binderkrantz, 2005, pp. 704-705).

More generally, scholars have pointed to three levels of factors influencing the political activities of groups and the resulting influence: institutional variation typically across countries; group level factors; and factors at the issue level (Dür and De Bièvre, 2007; Mahoney, 2007, p. 36). The last set of factors points to the importance of explaining not only variation in strategic choices across interest groups, but also variation in strategies used by a given group under different circumstances. To maximize political influence it is plausible that groups do not directly combine different strategies, but rather customize their use of strategies to the issue at hand. Incorporating the issue context in studies of group strategies is thus a necessary step toward mapping the logic of group strategic choices.

A drawback of the studies cited above is that they typically ask groups to generalize across the range of issues they are involved in. This enables general conclusions about the effect of, for example, group level variables such as resources and group type, but masks the role of factors related to the specific context groups work in. In their landmark book on the study of interest groups, Baumgartner and Leech pointed to the existence of on one hand a survey-based approach to studying the political role of interest groups and on the other a case study approach. Although case studies draw attention to the importance of contextual variables such as issue salience and degree of conflict these aspects are typically not incorporated in large $\mathrm{N}$-studies (Baumgartner and Leech, 1998, pp. 165-166).

Largely inspired by this observation, several attempts have been made to incorporate issue-related factors in group studies. It has been established that the issue context, for example, in terms of number of competitors and the public interest matters for strategies used by groups and eventually for their political success (Kollman, 1998; Leech, 1998; Mahoney, 2007). Attention has also been drawn to the importance of the political goals of groups. In a study of almost 100 issues Baumgartner et al (2009) find that groups working in 
defense of the status quo have a much better chance of realizing this goal than groups seeking policy change.

This latter finding points to the importance of group policy goals. By drawing attention to variation in group goals, we may gain some leverage in explaining strategic choices. In fact, the finding that groups use a wide range of tactics and strategies could mask that groups have different preferred strategies depending on what goals they are pursuing. With this focus we may also move the study of interest group activities closer to the way group leaders tend to perceive them. Asked about their choice of political activities, group leaders often reply 'it depends'. Although this statement may offhand indicate that it is not possible to systematically capture the factors affecting group tactics, it could also be taken as a challenge to investigate the context-specific factors on which group choices 'depend'.

\section{A framework of group goals}

Organizational goals may be defined and studied at different levels. Here, we focus on the collective goals of interest groups defined as the: 'desired state of affairs which the organization attempts to realize' (Etzioni, 1964, p. 19). Interest groups - along with other political organizations - may have goals focusing on internal as well as external matters (Mohr, 1973; Ainsworth and Sened, 1993). Organizational maintenance is, for example, a crucial goal for all political organizations, and some political activities may be engaged in because they are likely to attract new members and thus secure the survival of the group (Wilson, 1973, p. 30; Dunleavy, 1991; Lowery, 2007). Although this factor may explain some variation in strategy choice at the group level, our interest here is in the characteristics of the external policy-related goals and their consequences for political action.

This study considers the impact of group goals on four different strategies. In line with previous research we distinguish between 'insider' and 'outsider' strategies (Gais and Walker, 1991; Beyers, 2004; Binderkrantz, 2005; Eising, 2007; Kriesi et al, 2007). Insider strategies target decision makers directly and may be further divided into an administrative strategy focusing on the bureaucracy and a parliamentary strategy where MPs and parties are approached. With respect to outsider or indirect strategies, we include a general media strategy encompassing so-called 'responsible' media activities such as issuing press releases or contacting reporters (Grant, 2000b, pp. 135-136). Finally, we include a protest strategy to capture the types of activities that may be the hardest to reconcile with a close working relationship with bureaucrats (Grant, 2000a). This strategy includes tactics such as organizing strikes, direct action, public demonstrations and petitions. 
The distinction between different strategies organizes group activities according to the type of action involved. Another approach would be to distinguish between general types of communicative exchanges. Beyers thus proposes the dichotomy of bargaining versus arguing. Whereas bargaining involves the exchange of resources and information, arguing focuses on political ideas and arguments and seeking to induce change in the beliefs or preferences of other actors (Beyers, 2008, p. 1194). The bargaining mode is consistent with the widespread occurrence of close interaction between groups and civil servants described in many countries (Rhodes and Marsh, 1992; Öberg et al, 2011), whereas the arguing mode is more akin to the classic pluralist portrayal of pressure groups as external actors seeking influence through lobbying tactics (Truman, 1951).

A prerequisite for engaging in bargaining is that there is something to negotiate about. There are two relevant aspects of this. First, to be influential interest groups must possess resources valued by the political actors or institutions they interact with (Beyers, 2008, p. 1198). Second and more relevant for the present discussion, to facilitate this mode of interaction group goals must leave room for bargaining. According to Wilson, 'Bargaining is facilitated when the matter at issue is divisible - that is, when it is a matter of "more or less" rather than "all or nothing"' (Wilson, 1973, p. 285). The negotiation of salaries is, for example, a highly divisible issue, while a demand from an environmental group to protect an endangered species is more of an all or nothing nature.

Groups pursuing divisible goals are expected to seek direct interaction with decision makers. When bargaining is possible, it is crucial to get access to arenas where negotiation and exchange of resources may take place. A preference for the administrative and parliamentary strategy is therefore expected. In comparison, groups seeking the fulfillment of a non-divisible goal are more likely to go public. Here, the group strategy must focus on raising awareness of group goals, putting pressure on decision makers and convincing others about the appropriateness of the group's arguments and ideas (Beyers, 2008, p. 1195). ${ }^{1}$ The following hypotheses are therefore proposed:

Hypothesis 1a: Groups working for divisible goals will use the administrative and parliamentary strategy more intensively.

Hypothesis 1b: Groups working for non-divisible goals will use the media strategy and the protest strategy more intensively.

In their recent study of interest group influence in American politics, Baumgartner et al (2009) conclude that a crucial determinant of success is whether groups work to promote change or to block something that is on the agenda. Those wanting to protect the status quo benefit from the existence of 
a so-called 'coalition of the status quo', which prevents change by controlling access to the political system. Generally, change is much harder to achieve and groups seeking to change the status quo therefore face a difficult job, where they need to argue convincingly that a proposed alternative is better, but lack empirical evidence to support their cause (Beyers, 2008, p. 1199).

It might be expected that groups protecting the status quo would be mainly oriented toward bureaucrats and politicians. Such groups will aim to keep the issue in the secure hands of the coalition supporting the status quo. On the other hand, groups seeking change are expected to seek a widening of the scope of the policy conflict (Schattschneider, 1960). Hence, we expect groups seeking alternative political solutions to engage in a mode of arguing that targets the media and perhaps even includes protest activities. When groups seek political solutions that are radically different from the status quo they can be expected to distance themselves from the political system and pursue their causes through direct action or other types of public protest (Grant, 2000b, pp. 125-139). We therefore expect:

Hypothesis 2a: Groups working for change will use the media strategy and the protest strategy more intensively.

Hypothesis 2b: Groups working for the status quo will use the administrative strategy and the parliamentary strategy more intensively.

A third potential influence on strategies relates to the type of interest such groups pursue. Interest groups come in many different shades. Some organize the business community, some work for the interests of labor and others seek to protect the environment or promote human rights. The distinction between sectional groups promoting the interests of a specific, delimited constituency and public interest groups working for broader causes has attracted much attention from empirical as well as normative perspectives (Schattschneider, 1960; Berry, 1977, 1999; Gais and Walker, 1991). Group type has a demonstrated impact on strategic choices. Public interest groups have thus been found to be more engaged in media-directed activities, whereas sectional groups - in particular those organizing labor market interests - focus more on approaching the bureaucracy (Binderkrantz, 2008).

Although the distinction between sectional and public interest groups operates at the group level, there is also reason to expect variation in the type of interests pursued by a given group under different circumstances (Beyers, 2008). Groups generally working for broad causes sometimes pursue more narrow interests. Humanitarian or environmental groups may, for example, seek tax exemptions for contributions to their group. Likewise, business groups sometimes work for benefits accruing to a very narrow sector of the business community; in other instances they pursue broader business interests relating, 
for example, to the general regulation, expansion or contraction of the welfare state (Smith, 2000, p. 21). Groups may therefore sometimes work for goals that primarily benefit their immediate members and at other times pursue broader interests.

Whether a group promotes special or general interests is partly a matter of perception and framing. When groups are asked to classify their policy goals, we therefore measure group perception of goals rather than objective characteristics of goals. Further, groups may deliberately seek to portray their goals in terms of the public interest in order to attract support for their position (Rommetvedt, 2002). For example, unions representing public sector employees tend to argue that improving the working conditions of their members will benefit more general interests such as securing better schools or day care. Nevertheless, not all policy goals are equally easy to frame in general terms and group leaders may be expected to be conscious of the extent to which their primary aim to promote the interests of members or citizens more generally.

We expect policy goals reflecting narrow interests to raise the use of the administrative strategy, whereas policy goals reflecting broader interests will lead groups toward a more intensive use of the parliamentary, the media and the protest strategy. These expectations reflect the reasoning in the literature on patterns of strategy use at the group level (Beyers, 2004, p. 219; Binderkrantz, 2008). Broad interests are thus expected to be easier to defend in the media. When a group argues that it is protecting broad, societal interests it is natural to appeal to the population at large through the media, whereas policy goals based on narrow interests are likely to find more leverage among bureaucrats working on the subject in question (Jordan and Richardson, 1987, p. 26; Gais and Walker, 1991; Kollman, 1998, p. 51). In regard to the parliamentary strategy, Rommetvedt (2002) argues that appeals to parliament increasingly need to be framed in general terms, and we therefore also expect a positive effect of pursuing broad causes on this strategy. The expectations are therefore:

Hypothesis 3a: Groups working for policy goals pursuing special interests will use the administrative strategy more intensively.

Hypothesis 3b: Groups working for policy goals pursuing general interests will use the parliamentary strategy, the media strategy and the protest strategy more intensively.

A final aspect of group goals relates to how technically complicated a goal is. Some political goals are very simple and easy to communicate to any audience; others can hardly be explained without using technical language. A group wanting to block the building of a new highway through a valued nature 
area will have no trouble expressing this demand in a short statement, but an opposing interest group could find it much more challenging to express the technical calculations making that exact location preferable.

Policy goals of a technical nature are expected to lead to a more intensive use of the administrative strategy. Politicians often leave the more technical aspects of policies to bureaucrats and here groups may take advantage of their insight into such complicated issues. Technical insight is thus seen as one of the main resources interest groups offer in exchange for influence in administrative decision-making processes. In fact, interest groups may have more expertise on specific policies than civil servants and are therefore valued for the information they can provide (Johansen and Kristensen, 1982, p. 202; Browne, 1991; Öberg et $a l, 2011)$. On the other hand, when groups work for a policy goal of a more simple nature - something that may be expressed as a one-liner - they are more likely to approach politicians and the media as well as engage in a protest strategy. Here, groups have less to offer bureaucrats, but more to offer politicians and reporters who are interested in issues that easily present themselves to voters or readers (Rommetvedt, 2002; Wolfsfeld, 2011; Binderkrantz, 2012). Our propositions are thus:

Hypothesis 4a: Groups working for technical goals will use the administrative strategy more intensively.

Hypothesis 4b: Groups working for simple goals will use the parliamentary strategy, the media strategy and the protest strategy more intensively.

While some policy areas may generally be more technically complicated than others, different issues in the same area also have different characteristics, and as illustrated by the highway example above the goals of two groups working on the same issue may even differ in degree of technicality.

\section{Research Design}

To test the effect of different characteristics of group goals on political strategies it is necessary to investigate the political actions of many different interest groups pursuing many different policy goals. Therefore, a survey of groups was conducted. Here, it is possible to incorporate the relevant aspects of policy goals and relate them to political strategies. Specifically, the questionnaire asks groups to describe an issue they have been working on, the characteristics of group goals in relation to the issue, as well as, the tactics employed. Our unit of analysis is thus an interest group pursuing a specific policy goal. Ideally, more than one policy goal per interest group could have 
been investigated, but this would have required a much longer questionnaire and potentially a low response rate.

A challenge in conducting interest group surveys is the difficulty involved in identifying the relevant population of groups to survey (Berkhout and Lowery, 2008). We have benefitted from previous surveys conducted among Danish interest groups. Different scholars have over the years contributed to a list of interest groups based on registers of groups in different policy areas, web searches and registration of groups approaching parliament. The point of departure for our study was the list of groups utilized for a survey in 2004 (see Binderkrantz, 2005). Web searches were conducted for every group on the list and appropriate revisions made. To identify groups established after 2004, all group approaches to parliamentary committees and all groups consulted in administrative hearings of proposed bills in 2006-2007 were checked and new groups added to the list. The resulting list is a reasonable approximation of the Danish active interest group population, although we may have missed some groups that are active in ways that would not have been registered in our sources (Christiansen, 2012). The final list included 2000 groups (reduced to 1774 after a number of groups reported they had ceased activity or had no functioning contact information). The survey was carried out in 2008 as an e-mail-based survey. To increase the response level among non-responding groups, a randomly chosen subset received the questionnaire by mail. The overall response rate was 44.9 per cent. Among the responding groups, 182 non-politically active groups were excluded based on a series of questions about whether the group sought any kind of political influence, leaving 614 responses of relevance for the analyses.

The research question centers on the relation between characteristics of group goals and how such characteristics affect strategies pursued. A first step was therefore to identify a specific issue and a group policy goal in relation to this issue. Specifically, groups were asked to report upon a recent issue where the group had tried to achieve political influence. For this issue, groups provided a textual description first of the overall issue and then of the group goal in relation to the issue. Most groups answered these questions in a manner consistent with our understanding of issues and group goals, but a small number (approximately 5 per cent) either did not provide any text or reported that they had not recently been active in politics. These groups are left out of the analysis.

Interest group strategies are the dependent variables of the study. Strategies are overall approaches to seeking influence, whereas specific activities engaged in can be described as tactics (Milbrath, 1963, p. 41; Berry, 1977, p. 212). To establish measures of strategies, groups were asked about their use of a number of specific tactics related to the overall strategies. 
When the questions were introduced, groups were reminded to choose their answers depending on their use of tactics on a specific issue. Questions about the importance and frequency of use of specific tactics were asked. In constructing measures of strategies, the frequency of each tactic was weighted with its importance and an index for each strategy was constructed. Appendix lists the questions used in index construction. Cronbach's $\alpha$ for the indexes are between 0.7 and 0.9 . Indexes range from 0 to 100 .

With respect to the independent variables, policy goals are characterized according to the four dimensions discussed above. Groups were asked a battery of questions designed to capture these dimensions. The specific questions and the distribution of group answers are displayed in Table 1. On the basis of these questions, four indices were constructed with values of Cronbach's $\alpha$ ranging between 0.5 and 0.6. This is not impressive, but acceptable given the low number of questions included in the construction of each measure. Indexes range from 0 to 100 .

The analyses also include a number of other variables. First, type of interest group is particularly important because it affects whether groups pursue broad or narrow interests. The classification is made to distinguish between public interest groups and sectional groups as well as between groups representing labor, business and other specific constituents (Berry, 1977; Beyers, 2004; Jordan et al, 2004). In the analysis we distinguish between six types of groups.

1. Trade unions defined as associations of employees negotiating work terms and conditions.

2. Business groups representing the interests of business firms.

3. Institutional groups representing governmental units or institutions.

4. Identity groups representing, for example, patients, the elderly or ethnic groups.

5. Public interest groups where members do not have a selective interest in group goals.

6. Other groups, for example, hobby groups, occupational associations and religious groups.

Groups were coded into these categories by the authors based on group names, descriptions of group membership and web searches to determine issues of doubt. In a reliability test, an expert coder recoded 10 per cent of the groups resulting in a Cohen's $\kappa$ of 0.8 . In the regression analysis, dummy variables for each group type are included with 'other groups' as the reference category.

Also, we include a measure of group resources as these may affect the options groups generally have for being politically active and for bargaining with political actors. Here, we focus on staff size as a good measure of resources (Mahoney, 2007, p. 41). Specifically, the number of employees working with 


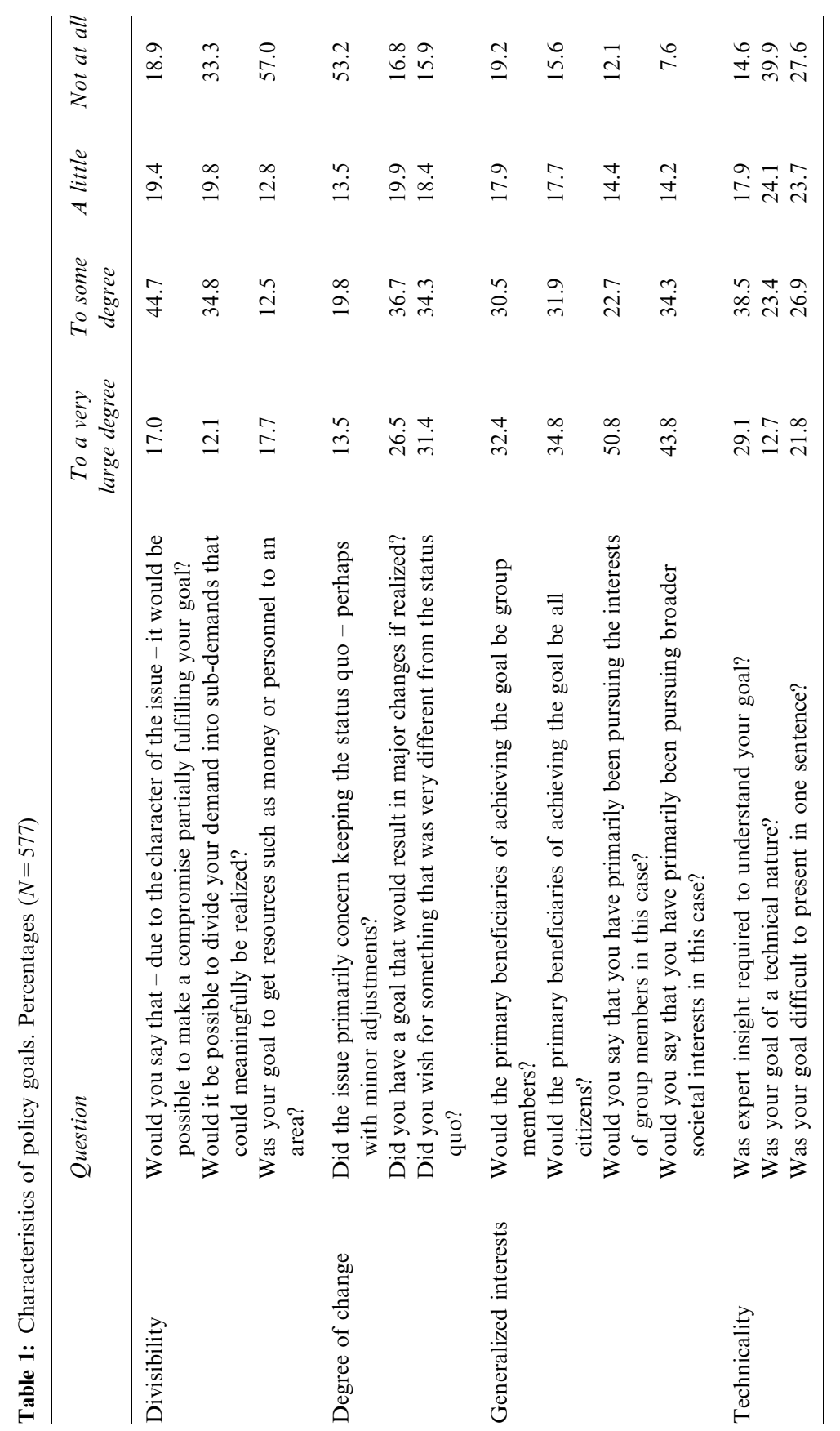


politics is included. In order to obtain linearity the measure has been logarithmically transformed. Lastly, we have constructed a measure of corporative integration based on a number of questions aiming to capture group involvement in administrative decision making. Again, the questions specifically referred to the issue in question. Appendix lists the questions used in index construction. The value of Cronbach's $\alpha$ for this index is 0.8 and the index ranges from 0 to 100 .

\section{Interest Group Goals and Political Strategies}

\section{Exploring the nature of group goals}

What characterizes the policy goals interest groups are pursuing? Do groups primarily work to achieve benefits for group members or do they seek to advance broader causes? And how many groups work for change and how many to protect the status quo? These questions can be addressed by analyzing the characteristics of group policy goals. Table 1 displays the distribution of group answers to a range of questions tapping the four overall dimensions of group goals. An advantage of the research design is that we have not only asked groups to characterize their policy goal, but also for a textual description of goals. In the discussion, we are therefore able to provide specific examples of the types of goals found on both ends of the goal dimensions.

It is evident that group policy goals vary considerably. The first set of questions aims to tap whether interest groups work for goals that may only be met fully or not at all - or put differently whether the goal is divisible. Asked if it would be possible to make a compromise partially fulfilling their goal, 17 per cent answer 'to a very large degree', while about 19 per cent say 'not at all'. The remaining groups provide more nuanced answers with almost 45 per cent saying 'to some degree'. Apparently, some room for negotiation is most common when groups pursue their policy goals. Some group goals may even be divided into sub-demands that could meaningfully be realized, although one-third report that this is not possible for the goal they are pursuing.

In the final question, groups were asked if the goal they were pursuing involved obtaining resources. By definition, this can be seen as a divisible goal because resources are continuous. For about 18 per cent of groups the goal was 'to a very large degree' resource-related, whereas 57 per cent answer 'not at all'. A divisible resource-related goal could be raising public subsidies to newspaper distribution, and a divisible goal that does not necessarily involve resources could be raising awareness about teaching in prisons. These goals are clearly divisible and can be met to any degree. On the other hand, in a reasonable number of instances, no options for finding a compromise exist. For example, 
a group works to prevent the change of a specific test from a written to an oral examination, whereas another works to abolish a ban on private lama keeping.

The next dimension focuses on the relation between what an interest group wants and the political status quo. Most groups are not working to protect the status quo: about 53 per cent answer 'not at all'. In fact, major change would definitely be the result if 26.5 per cent of groups had their way and to some degree' for about 37 per cent of the groups. A similar pattern is found when groups are asked whether they wish for something very different from the status quo. Even though most groups pursue change, a sizeable minority works to protect the status quo: 13.5 per cent 'to a very large degree' and almost 20 per cent 'to some degree'. Among these are a group seeking to prevent cuts in funding of private schools and a group that wants to keep a ferry running between Copenhagen and the island of Bornholm. These goals can be contrasted with goals involving changes such as abolishing the military, ensuring a referendum about a specific EU treaty or establishing tighter relations between Skaane (Danish territory until 1658 and now part of Sweden) and Denmark.

Next, a set of questions focuses on the type of interests pursued. More than 60 per cent of the groups report that their members are the primary beneficiaries (at least to some degree) if the groups achieve their goals, but about 66 per cent state that all citizens will benefit if the group is successful. In other words, there is not necessarily a contradiction between working for members and for broader interests. As discussed above, this may demonstrate that group goals immediately benefiting members can often be framed as benefiting a larger public. Still, for every question a sizeable number of groups answer 'a little' or 'not at all' and the dimension therefore seems relevant for understanding group goals. Examples also demonstrate real differences in the type of goals pursued. Some groups report working to legalize euthanasia or to combat invasive species - issues where general interests are at stake. Other groups seek better assistance for deaf and blind people or even the legalization of keeping a specific type of animal. Even though larger societal benefits could be imagined, these latter causes have clear target groups that will benefit if the group is successful.

As far as the last dimension capturing how technical versus simple goals are, most groups say that expert insight is required to fully understand their policy goals. About 65 per cent answer at least 'to some degree' in response to this question. Group goals are not necessarily of a technical nature - this is the case at least to some degree for about 36 per cent - but they are nevertheless complicated enough to require expert insight. Many groups report that it is somewhat complicated to present their policy goal in a single sentence. Still, close to 28 per cent have no difficulty reducing their objectives to a short 
statement and a fair share also states that there is no need for expert insight to understand what they work for. Again, this is evidence of large variation in the causes groups pursue. Among groups with relatively simple goals we find a group working to reduce shop opening hours on Sundays and another group arguing for increased development aid. Examples of more complicated goals are tight EU-standards for seeds and acknowledgement of repetitive strain injuries.

Overall, the evidence illustrates that interest groups pursue many different policy goals. Some groups take their membership interests as point of departure; others work for broader goals. Some seek divisible goals, for example, in terms of resources to a specific area; others have more absolute goals. Some groups work for rather technical issues; others work for things that are easily comprehended. Finally, some groups work to protect the status quo, while others seek major change. There is therefore good reason to investigate variation across different types of groups in goals pursued as well as the effect of group goals on strategies pursued.

\section{Variation in group goals}

The examples provided above may give a first hint of a possible relation between type of group and the characteristics of policy goals pursued. For many goals it is not hard to guess what kind of group is pursing the goal, whereas other goals could presumably be ascribed to rather different kinds of groups. In Table 2 variation among group types in regard to type of policy goal is analyzed.

Table 2: Group type and goal characteristics. Mean index scores $(N=577)$

\begin{tabular}{lcccrr}
\hline & Divisibility & $\begin{array}{c}\text { Degree of } \\
\text { change }\end{array}$ & $\begin{array}{c}\text { Generalized } \\
\text { interests }\end{array}$ & Technicality & $N$ \\
\hline Trade unions & 48.7 & 63.2 & 48.8 & 52.4 & 78 \\
Business groups & 37.4 & 59.6 & 41.3 & $56.7^{\mathrm{f}}$ & 151 \\
Institutional groups & $53.1^{\mathrm{a}}$ & 53.4 & 48.8 & 48.2 & 41 \\
Identity groups & 44.4 & $69.7^{\mathrm{b}}$ & 48.5 & 40.9 & 98 \\
Public interest groups & 38.9 & $74.6^{\mathrm{c}}$ & $69.5^{\mathrm{d}}$ & 40.5 & 74 \\
Other groups & 39.1 & 55.2 & $55.6^{\mathrm{e}}$ & 45.8 & 135 \\
All groups & 41.8 & 62.3 & 51.0 & 48.2 & 577 \\
\hline
\end{tabular}

Notes: All dependent variables range from 0 to 100 with 100 indicating: high divisibility, high degree of change sought, highly generalized interests and highly technical goals. Significant differences according to a Scheffe test (at the 0.05 level): ${ }^{a}$ higher than business groups; ${ }^{\text {b higher than }}$ other groups; " higher than business groups, institutional groups and other groups; ${ }^{\mathrm{d}}$ higher than all other group categories; ' higher than business groups; ${ }^{\mathrm{f}}$ higher than identity groups, public interest groups and other groups. 
Although there are some differences in the average score on the index capturing whether goals may be partially or only fully met, the only significant difference is that the goals of institutional groups are more divisible than those of business groups. There is thus no clear relation between group type and this dimension of group goals. This is on the other hand the case for the other dimensions. There are three main patterns: First, identity groups and public interest groups tend to seek change, whereas institutional groups, other groups and business groups are predominantly status quo supporters. Second, public interest groups pursue broader interests than all other group types and third, business groups are more likely to pursue technical goals than identity groups, public interest groups and other groups.

The overall picture depicts public interest groups in a special position. These groups work for broad societal interests, they pursue major changes and their goals are relatively simple and non-technical. This pattern is consistent with the special role ascribed to public interest groups in the literature (Berry, 1977). Identity groups are comparable to public interest groups in terms of degree of technicality and degree of change sought but more prone to pursue the interests of their group members. The major difference between these two group types is exactly that identity groups organize a delimited membership such as women, elderly or patients, and the empirics demonstrate that these groups in fact work to advance the interests of their members. The distinction between public interest groups and identity groups thus captures real differences in types of goals pursued, which is masked by grouping these in an overall citizen or social movement group category (Kriesi et al, 2007; Mahoney, 2007).

Business groups have the lowest score of all group types in degree of generalized interests sought, and they pursue more technically complicated goals than other group types (although not all differences are significant). This picture corresponds to the reasoning found in the network approach as well as the corporatist literature, where business groups are argued to have a particularly close working relationship with the bureaucracy in many policy areas owing to the technical insight they can provide (Johansen and Kristensen, 1982; Rhodes and Marsh, 1992). Trade unions are relatively close to business groups on all dimensions, but are somewhat more prone to pursue general interests (difference not significant). This may indicate that Olson is right in pointing out that some trade unions may become encompassing enough to work for the common good (Olson, 1982, pp. 47-53). Lastly, institutional groups - that is associations of governmental units or institutions - stand out as working for divisible issues and protecting the status quo. These groups indirectly financed by public money - are thus a potentially conservative force in the political system as they strive to avoid budget cuts or deterioration of services in their area. 
The systematic variation in type of goals pursued by different groups raises the interesting question about the relation between group type, policy goals and political strategies pursued. The next analytical step is therefore to see whether the expected relationships between group goals and preferred political strategy exist. Here, group type is included in the analyses - alongside measures of resources - enabling an analysis of whether goals affect strategies independent of group type, or may only matter because they differ systematically across group types. Table 3 presents the results of multivariate analyses of the four influence strategies. The analyses are conducted in two steps. First, only variables related to group type and resources are included, and in the next step the four measures of policy goals are also entered. The two-step approach enables the analysis of whether including aspects of policy goals adds explanatory power to a model including basic group variables. Also, it is possible to see how the effect of group type is affected by including measures of policy goals.

The most important finding is that the characteristics of group goals do affect the type of strategies interest groups choose when they seek political influence. Adding measures of policy goals to the analyses improves the explanatory value of the models, and three of the four dimensions of goals affect at least one political strategy - even when we control for type of group and group resources. It appears that interest group leaders are right when answering 'it depends' to questions about their strategy of choice. Groups do not simply have a preferred pattern of political activities across all cases they are involved in, but rather adapt their strategies to the situation at hand (Baumgartner and Leech, 1998; Leech, 1998).

The effects of goal divisibility are surprisingly broad. In fact, the more divisible goals are, the more actively groups use all strategies. This aspect does not affect the choice between strategies, but rather how active groups generally are. Following Wilson (1973, p. 285) and Rommetvedt (2002, pp. 58-67) groups were expected to seek direct access to decision makers when pursuing divisible goals because such goals left room for negotiation. The results, however, indicate that no arena is superior in this respect. We can thus confirm $\mathrm{H} 1 \mathrm{a}$ about a positive effect on the use of direct strategies, but the findings are not in accordance with $\mathrm{H} 1 \mathrm{~b}$ since high divisibility also affects indirect strategies positively.

A surprising finding is that it makes no difference whether groups work to obtain large changes or to protect the status quo. Groups working for change were expected to engage in the media strategy and the protest strategy in order to widen the scope of the conflict and raise awareness of their proposed alternative policies, whereas those protecting the status quo were expected to use relations to decision makers to try to block change. These expectations as expressed in $\mathrm{H} 2 \mathrm{a}$ and $\mathrm{H} 2 \mathrm{~b}$ are not supported by the analyses. There are several 


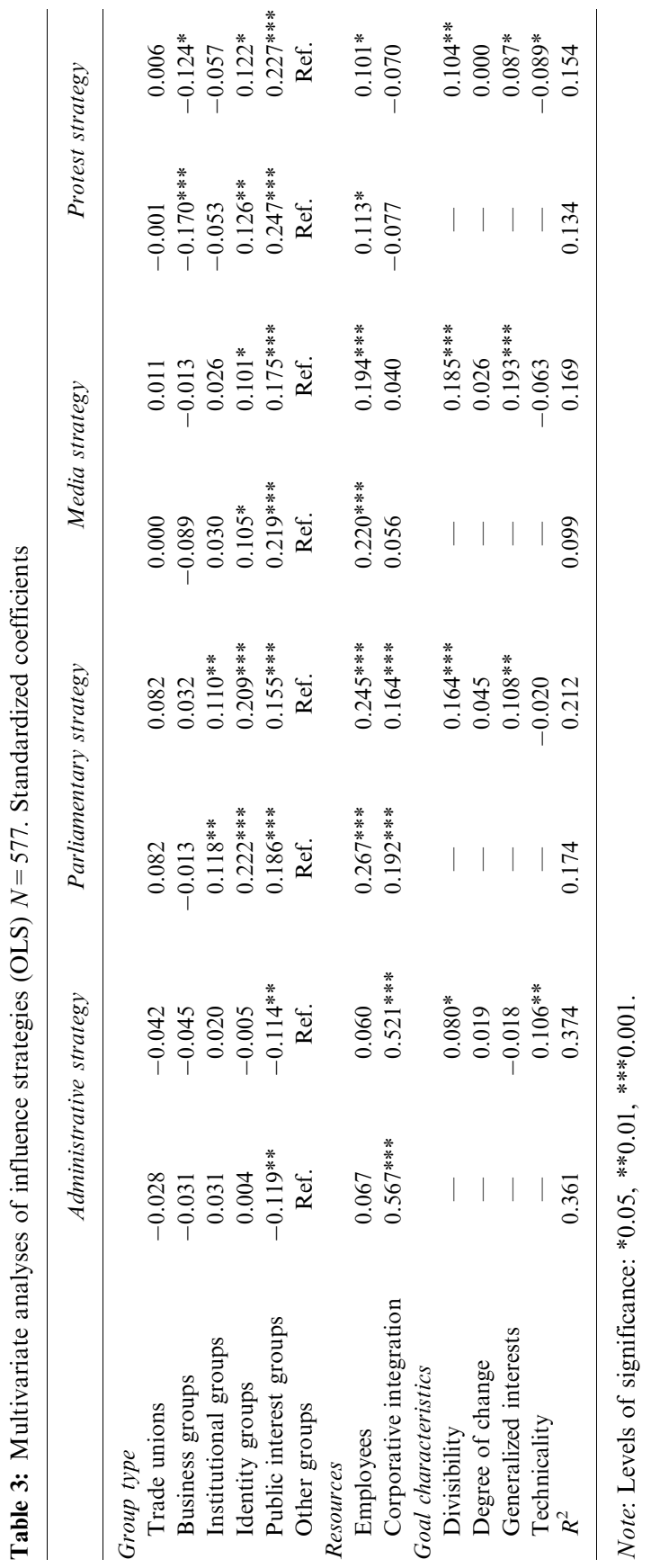


possible explanations for this finding. First, this dimension of policy goals may be more important for success than for strategies engaged in (Baumgartner et al, 2009). Second, it is worth noting that rather few groups (13.5 per cent) in the study report protecting the status quo to a very large degree. Groups may be more likely to report on issues where they seek some type of political change rather than on issues where they merely try to prevent others from having their way. Third, there are in fact positive bivariate relationships between working for change and using the parliamentary, the media and the protest strategy (numbers not shown). This relation disappears when we control for group type, indicating that the role of change may be related to the types of groups working for major changes as opposed to protecting the status quo.

The effect of the remaining two goal dimensions are more in line with expectations. Thus, as expected in H3b, groups pursuing general interests in respect to a given issue are more likely than other groups to use a media strategy. They are also somewhat more active toward parliament and more prone to engage in confrontational activities. The effect on the administrative strategy is negative but not significant (contrary to the expectation in $\mathrm{H} 3 \mathrm{a}$ ). It is interesting to compare the effect of this goal characteristic with the effect of group type. Above, we saw that public interest groups more often than other groups work for broad causes. Significantly, this pattern is repeated here even when group type and policy goals are included in the same model. Public interest groups are less active toward the administration and more in the other channels - and they share this pattern of engagement with identity groups (although the coefficient in relation to the administrative strategy for identity groups is not significant). In other words, it makes a difference if a group pursues general interests in a given case, but group type is also important in itself.

With respect to the degree of technicality of group goals we also find the expected patterns. When goals require expert insight to comprehend and are not easily reduced to a simple statement, groups are more active toward the administration (in accordance with $\mathrm{H} 4 \mathrm{a}$ ). In the opposite situation, groups use the protest strategy more intensively. There is no effect on the use of the parliamentary strategy and the media strategy and we can thus regard $\mathrm{H} 4 \mathrm{~b}$ as partially confirmed. These findings support Johansen and Kristensen's (1982) point that interactions between groups and bureaucrats are particularly intensive when technical issues are at stake.

The results indicate a complicated relation between group type, policy goals and influence strategies. First, there is clearly a relation between group type and policy goals. Second, the overall pattern illustrates direct effects of group type and policy goals on strategies used - and a higher explanatory power when both sets of variables are included. Third, there also seems to be a more indirect effect where group type affects policy goals, which in turn affect 
strategies used. All effects of group types are thus reduced when characteristics of policy goals are included in the models. These findings illustrate that policy goals matter, but also that there is more to group type than the element of the goals of different groups. In particular, the relation to group members may be of importance (Ainsworth and Sened, 1993). Public interest groups draw their members from the public at large and may therefore engage in more publicoriented strategies in order to communicate with members and potential members - independent of the type of goals they are pursuing (Wilson, 1973, pp. 8-9; Grant, 2000b, p. 134; Binderkrantz, 2008).

\section{Conclusion}

Interest groups engage in politics pursue policy-related goals. Some groups seek benefits for very specific segments of society; others work for broader causes. Some groups have aims that are highly divisible; others work for goals that may only be met fully or not at all. The present analysis illustrates the divergence of group policy goals and establishes that groups do customize their strategies to the policy goal pursued. The results may be summarized as reflecting three overall logics: a general logic of activity, where groups with more resources and goals that may be partially accommodated are more active than other groups; a logic of the bureaucracy, where groups working with rather complicated goals are more active toward bureaucrats; and a logic of parliament and the media, where public interest groups, identity groups and groups pursuing general interests in specific cases are more active.

With the incorporation of policy goals in a group survey, this study has contributed to a better integration of contextual factors in a quantitative study (Baumgartner and Leech, 1998). Naturally, the research design may have some limits. Whether group goals have been thoroughly captured by the four aspects in the study is notoriously difficult to establish. Still, the four measures capture at least sufficiently important aspects of group goals to illustrate their role in relation to strategic behavior. Further studies may delve more into the nature of goals, for example, by comparing issues considered by the administration and issues taken up by the media and the goals of involved groups. Also, it may be interesting to investigate the relation between group type and policy goals more closely by studying the involvement of the same group across several issues, where the group may have different types of goals.

Finally, it is worth emphasizing the variation in the policy goals of the participating groups. The combination of systematic measures of policy goals and textual descriptions of group goals has demonstrated the impressive range of goals pursued by interest groups. It appears that almost any imaginable 
cause has found an advocate. Evidently, having an interest group advocate a policy goal does not equal political success. Nevertheless, it illustrates the degree of diversity in interest group work. From a normative perspective, valuing the freedom to pursue different goals, this can be seen as a reassuring finding.

\section{Note}

1 In situations where a group is pursuing multiple goals or where side-payments, for example, in terms of future support are possible there may still be room for negotiation (Wilson, 1973, p. 285; Rommetvedt, 2002, p. 64).

\section{References}

Ainsworth, S. and Sened, I. (1993) The role of lobbyists: Entrepreneurs with two audiences. American Journal of Political Science 37(3): 834-866.

Baumgartner, F.R., Berry, J.M., Hojnacki, M., Kimball, D.C. and Leech, B.L. (2009) Lobbying and Policy Change. Who Wins, Who Loses, and Why. Chicago, IL: The University of Chicago Press.

Baumgartner, F.R. and Leech, B.L. (1998) Basic Interests. The Importance of Groups in Politics and in Political Science. Princeton, NJ: Princeton University Press.

Berkhout, J. and Lowery, D. (2008) Counting organized interests in the European union: A comparison of data sources. Journal of European Public Policy 15(4): 489-513.

Berry, J.M. (1977) Lobbying for the People. The Political Behavior of Public Interest Groups. Princeton, NJ: Princeton University Press.

Berry, J.M. (1999) The New Liberalism. The Rising Power of Citizen Groups. Washington DC: The Brookings Institution.

Beyers, J. (2004) Voice and access. Political practices of European interest associations. European Union Politics 5(2): 211-240.

Beyers, J. (2008) Policy issues, organisational format and the political strategies of interest organisations. West European Politics 31(6): 1188-1211.

Binderkrantz, A. (2005) Interest group strategies: Navigating between privileged access and strategies of pressure. Political Studies 53(4): 694-715.

Binderkrantz, A. (2008) Different groups, different strategies: How interest groups pursue their political ambitions. Scandinavian Political Studies 31(2): 173-200.

Binderkrantz, A. (2012) Interest groups in the media. Bias and diversity over time. European Journal of Political Research 51(1): 117-139.

Browne, W.P. (1991) Issue niches and the limits of interest group influence. In: A.J. Cigler and B.A. Loomis (eds.), Interest Group Politics, 3rd edn. Washington DC: CQ Press.

Christiansen, P.M. (2012) The usual suspects: Interest group dynamics and representation in Denmark. In: D. Halpin and G. Jordan (eds.), The Scale of Interest Organization in Democratic Politics. Data and Research Methods. Houndmills, UK: Palgrave/McMillan.

Dunleavy, P. (1991) Democracy, Bureaucracy and Public Choice. Economic Explanations in Political Science. New York: Harvester/Wheatsheaf.

Dür, A. and De Bièvre, D. (2007) The question of interest group influence. Journal of Public Policy 27(1): 1-12. 
Eising, R. (2007) Institutional context, organizational resources and strategic choices: Explaining interest group access in the European union. European Union Politics 8(3): 329-362.

Etzioni, A. (1964) Modern Organizations. Upper Saddle River, NJ: Prentice-Hall.

Gais, T.L. and Walker Jr, J.L. (1991) Pathways to influence in American politics. In: L.J. Walker, Jr (ed.), Mobilizing Interest Groups in America. Patrons, Professions and Social Movements. Ann Arbor, MI: The University of Michigan Press.

Grant, W. (2000a) Insider groups, outsider groups and interest group strategies in Britain. In: R.A.W. Rhodes (ed.), United Kingdom, Vol. 1. Aldershot, UK: Ashgate.

Grant, W. (2000b) Pressure Groups and British Politics. London: MacMillan Press ltd.

Grant, W. (2004) Pressure politics: The changing world of pressure groups. Parliamentary Affairs 57(2): 408-419.

Heinz, J.P., Laumann, E.O., Nelson, R.L. and Salisbury, R.H. (1993) The Hollow Core. Private Interests in National Policy Making. Cambridge, MA: Harvard University Press.

Johansen, L.N. and Kristensen, O.P. (1982) Corporatist traits in Denmark, 1946-1976. In: G. Lembruch and P. Schmitter (eds.), Patterns of Corporatist Policy-Making. London: Sage Publications.

Jordan, G. and Richardson, J.J. (1987) Government and Pressure Groups in Britain. Oxford: Clarendon Press.

Jordan, G., Halpin, D. and Maloney, W. (2004) Defining interests: Disambiguation and the need for new distinctions. British Journal of Politics and International Relations 6(2): 195-212.

Kollman, K. (1998) Outside Lobbying: Public Opinion and Interest Group Strategies. Princeton, NJ: Princeton University Press.

Kriesi, H., Tresch, A. and Jochum, M. (2007) Going public in the European union: Action repertoires of Western European collective political actors. Comparative Political Studies 40(1): $48-73$.

Leech, B.L. (1998) Lobbying strategies of American interest groups. Dissertation at Texas A\&M University.

Lembruch, G. (1982) Patterns of Corporatist Policy Making. London: Sage Publications.

Lowery, D. (2007) Why do organized interests lobby? A multi-goal, multi-context theory of lobbying. Polity 39(1): 29-54.

Mahoney, C. (2007) Lobbying success in the United States and the European Union. Journal of Public Policy 27(1): 36-56.

Mahoney, C. (2008) Brussels versus the Beltway. Advocacy in the United States and the European Union. Georgetown, Washington DC: Georgetown University Press.

Marsh, D., Toke, D., Belfrage, C., Tepe, D. and McGough, S. (2009) Policy networks and the distinction between insider and outsider groups: The case of the countryside alliance. Public Administration 87(3): 621-638.

Milbrath, L.W. (1963) The Washington Lobbyists. Chicago, IL: Rand MacNally \& Company.

Mohr, L.B. (1973) The concept of organizational goal. The American Political Science Review 67(2): 470-481.

Öberg, P., Svensson, T., Christiansen, P.M., Nørgaard, A.S., Rommetvedt, H. and Thesen, G. (2011) Disrupted exchange and declining corporatism: Government authority and interest group capability in Scandinavia. Government and Opposition 46(3): 365-391.

Olson, M. (1982) The Rise and Decline of Nations. New Haven, CT: Yale University Press.

Rhodes, R.A.W. and Marsh, D. (1992) New directions in the study of policy networks. European Journal of Political Research 21(1-2): 181-205.

Rommetvedt, H. (2002) Politikkens allmenngjoring og den ny-pluralistiske parlamentarismen. Bergen, Norway: Fagbokforlaget Vigmostad \& Bjørke AS.

Schattschneider, E.E. (1960) The Semisovereign People: A Realists View at Democracy in America. New York: Holt, Rienhart and Winston. 
Schlozman, K.L. and Tierney, J.T. (1986) Organized Interests and American Democracy. New York: Harper and Row.

Schmitter, P. (1981) Interest intermediation and regime governability in contemporary Western Europe and North America. In: S. Berger (ed.), Organizing Interests in Western Europe. Cambridge, UK: Cambridge University Press.

Smith, M.A. (2000) American Business and Political Power. Public Opinion, Elections, and Democracy. Chicago, IL: The University of Chicago Press.

Truman, D.B. (1951) The Governmental Process. Political Interests and the Public Opinion. New York: Alfred A. Knopf.

Wilson, J.Q. (1973) Political Organizations. New York: Basic Books, Inc.

Wolfsfeld, G. (2011) Making Sense of Media \& Politics. Five Principles in Political Communication. New York: Routledge.

\section{Appendix}

Group types, indicators of influence strategies and indicators of privileged position

1. Indicators of influence strategies Administrative strategy

- Contacting national public servants.

- Responding to requests for comments.

- Active use of public committees and other bodies.

Parliamentary strategy

- Contacting parliamentary committees.

- Contacting party spokespersons.

- Contacting other members of parliament.

- Contacting party organizations.

Media strategy

- Paid advertisements in newspapers and so on.

- Contacting reporters.

- Issuing press releases and holding press conferences.

- Writing letters to the editor and columns.

- Encouraging members and others to write letters to the editor.

Protest strategy

- Strikes, civil disobedience and illegal direct action.

- Legal direct action, public demonstrations and happenings.

- Conducting petitions. 
2. Indicators of privileged position

- The group receives bills and administrative regulations or similar for comments.

- The group was represented in public committees, boards, commissions or similar.

- The group was asked about the statutes for committees, boards or similar.

- The group was asked about the composition of committees, boards or similar.

- The group was contacted by civil servants. 